\title{
Deuterium trapping in tungsten deposition layers formed by deuterium plasma sputtering
}

\author{
V.Kh. Alimov ${ }^{1, *}$, J. Roth $^{2}$, W.M. Shu ${ }^{3}$, D.A. Komarov ${ }^{4}$, K. Isobe $^{1}$, T. Yamanishi ${ }^{1}$ \\ ${ }^{1}$ Tritium Technology Group, Japan Atomic Energy Agency, Tokai, Ibaraki 319-1195, Japan \\ ${ }^{2}$ Max-Planck-Institut für Plasmaphysik, EURATOM Association, D-85748 Garching, Germany \\ ${ }^{3}$ ITER International Organization, CEA Cadarache, 13108 Saint Paul-lez-Durance, France \\ ${ }^{4}$ Institute of Physical Chemistry and Electrochemistry, Russian Academy of Sciences, 119991 \\ Moscow, Russia
}

\begin{abstract}
A study of the influence of the deposition conditions on the surface morphology and deuterium (D) concentration in tungsten (W) deposition layers formed by magnetron sputtering and in the linear plasma generator has been carried out. Thick W layers $(\geq 0.4$ $\mu \mathrm{m})$ deposited onto copper substrates demonstrate areas of pilling and, after postdeposition heating to $1300 \mathrm{~K}$, flaking-off and fracturing. For thin $\mathrm{W}$ layers $(\leq 80 \mathrm{~nm})$ deposited onto stainless steel (SS) and W substrates, no areas of flaking-off and fracturing exist both after deposition and after post-deposition heating to $673 \mathrm{~K}$ for the SS substrate and to $1300 \mathrm{~K}$ for the $\mathrm{W}$ substrate. The concentration of deuterium in the $\mathrm{W}$ layers was found to decrease with increasing substrate temperature and with increasing tungsten deposition rate. For layers with relatively high concentration of oxygen $(0.20-0.60 \mathrm{O} / \mathrm{W})$, a decrease of the $\mathrm{D}$ concentration with increasing substrate temperature is more pronounced than that for layers deposited in good vacuum conditions. To describe the evolution of the $\mathrm{D} / \mathrm{W}$ ratio with the substrate temperature and the tungsten deposition rate, an empirical equation proposed by De Temmerman and Doerner [J. Nucl. Mater. 389 (2009) 479] but with alternative parameters has been used.
\end{abstract}

\footnotetext{
* Corresponding author. Tel.: +81 29282 6452; fax: +81 292825917.

E-mail address: alimov.vladimir@jaea.go.jp (V.Kh. Alimov).
} 


\section{Introduction}

Tungsten (W) is a candidate material for plasma facing high heat-flux structures in the divertor area of tokamak fusion reactors [1]. As plasma facing material, $\mathrm{W}$ will be subjected to high-flux low energy particle bombardment including fuel hydrogen isotopes and helium ash. In this environment, tungsten will be eroded, and eroded particles emitted from the plasma facing materials will form re-deposited layers in areas not in direct contact with the plasma. Due to mechanical and thermal stresses inside the layers, they can flake once they have grown to a certain thickness and produce dusts of different sizes (typically from $10 \mu \mathrm{m}$ to few $\mathrm{mm}$ ) [2]. In order to estimate the tritium inventory in the vessel of ITER and future fusion reactors, it is necessary to investigate hydrogen isotope retention in the $\mathrm{W}$ re-deposited layers. A large number of publications was devoted to hydrogen isotope retention in $\mathrm{W}$ materials exposed to hydrogen ions with energies below the displacement and sputtering thresholds (see Ref. [3] and references therein). However, only limited experimental investigations aimed at understanding hydrogen isotope retention in $\mathrm{W}$ layers deposited on collector probes due to sputtering of $\mathrm{W}$ targets with deuterium ions [4] and hydrogen and deuterium plasmas [5, 6] have been performed. In experiments with $1.5 \mathrm{keV}$ D ions no co-deposition of reflected deuterium with sputtered tungsten was observed at room temperature. It was therefore concluded that the concentration of $\mathrm{D}$ atoms in the $\mathrm{W}$ deposition layer was below a few percent [4]. On the other hand, in $\mathrm{W}$ layers deposited in a hydrogen RF plasma at a substrate temperature of about $430 \mathrm{~K}$, the ratio of hydrogen to tungsten atoms was observed to be $0.15 \mathrm{H} / \mathrm{W}$ [5]. A study of the influence of the deposition conditions on the deuterium retention in codeposited $\mathrm{W}$ layers formed by both magnetron sputtering and in the PISCES-B linear device [6] showed that the $\mathrm{D}$ concentration decreased with increasing deposition rate and increasing temperature, and increased for increasing energy of the impinging particles.

The purpose of this work was to obtain new data on deuterium concentration in tungsten deposition layers formed by sputtering $\mathrm{W}$ targets in deuterium plasmas over a wide range of the $\mathrm{W}$ deposition rate, focusing on low values of this parameter. The tungsten concentration in the deposition layers was determined by Rutherford backscattering spectrometry, whereas the $\mathrm{D}\left({ }^{3} \mathrm{He}, \mathrm{p}\right){ }^{4} \mathrm{He}$ nuclear reaction at different ${ }^{3} \mathrm{He}$ energies was used for quantitative $\mathrm{D}$ depth profiling. 


\section{Experimental}

\subsection{Deposition using magnetron plasma}

Two sets of tungsten deposition layers were prepared by sputtering of a $\mathrm{W}$ target by low-energy deuterium plasmas. The first set of $\mathrm{W}$ layers was deposited in a magnetron system (IPCE, Moscow) with a typical background pressure $<10^{-3} \mathrm{~Pa}$ by dc sputtering of a W cathode in $\mathrm{D}_{2}$ and mixed $\mathrm{Ar}+\mathrm{D}_{2}$ atmospheres [7,8]. During the plasma discharge, the pressure of $D_{2}$ and $A r+D_{2}$ gas mixture was fixed at $1 \mathrm{~Pa}$, while the fraction of $\mathrm{Ar}$ in the gas mixture was about $40 \%$. The $\mathrm{W}$ cathode surface was bombarded with plasma ions accelerated in the cathode sheath of the magnetron discharge with a discharge voltage of $400 \pm 40 \mathrm{~V}$ and discharge current of $0.6 \mathrm{~A}$. For assessment of the ion energy, the spatial distribution of the plasma potential was measured using Langmuir probes. The measurements showed that the cathode-drop voltage was about 0.85 of the discharge voltage. Reasoning that $\mathrm{D}_{2}{ }^{+}$ions dominate in the plasma, the mean energy of $\mathrm{D}$ and $\mathrm{Ar}$ ions was estimated to be $170 \mathrm{eV} / \mathrm{D}$ and $340 \mathrm{eV} / \mathrm{Ar}$, respectively. Tungsten layers were deposited onto specially prepared $\mathrm{Cu} / \mathrm{Si}$ substrates ${ }^{1}(0.5 \mu \mathrm{m}$ thick $\mathrm{Cu}$ layers deposited on $\mathrm{Si}$ plates). $\mathrm{Cu}$ was chosen as a material for the intermediate layer because it does not form an alloy with $\mathrm{W}$ and thus avoids any potential mixing at the $\mathrm{W}-\mathrm{Cu}$ interface. These substrates were fixed on a substrate holder equipped with a resistance heater. The holder was located over the cathode at a distance of $6 \mathrm{~cm}$. During the deposition process, the substrate temperature, $T$, was monitored by a chromel-alumel thermocouple and was adjusted in the range from 303 to $653 \mathrm{~K}$. The deposition time was 90 and 15 min for the pure D plasma and Ar-seeded D plasma, respectively.

\subsection{Deposition using linear plasma generator}

The second set of $\mathrm{W}$ deposition layers was prepared in the linear plasma generator (LPG) at JAEA kept under good vacuum condition $\left(10^{-6} \mathrm{~Pa}\right)[9,10]$. A W disc, $50 \mathrm{~mm}$ in

\footnotetext{
${ }^{1}$ Coefficients of thermal expansion for copper and stainless steel are close in value (about 17 $\mathrm{ppm} /{ }^{\circ} \mathrm{C}$ and $11-19 \mathrm{ppm} /{ }^{\circ} \mathrm{C}$, respectively), while for tungsten this coefficient is equal to $4 \mathrm{ppm} /{ }^{\circ} \mathrm{C}$. The intermediate $\mathrm{Cu}$ layer was used to examine adhesion stability of $\mathrm{W}$ layers deposited onto stainless steel components in the ITER divertor area.
} 
diameter, was fixed in the target holder with the help of a Mo ring and was exposed to a ${ }^{4} \mathrm{He}$-seeded D plasma generated in a $\mathrm{He}+\mathrm{D}_{2}$ gas mixture. The He partial pressure in the plasma generation section was $2 \times 10^{-1} \mathrm{~Pa}$, whereas the $\mathrm{D}_{2}$ partial pressure was fixed at $1 \mathrm{~Pa}$. In doing so, a plasma beam with species of $\mathrm{D}_{2}^{+}$(over $75 \%$ ) and $\mathrm{D}^{+}$(less than $15 \%$ ) was obtained [9]. The concentration of He ions in the He-seeded D plasma was estimated to be $10 \%$ from measured sputtering yields of $\mathrm{W}$ target [11].

The energies of deuterium and helium ions were determined from the bias voltage of $-200 \mathrm{~V}$ applied to the $\mathrm{W}$ target and the plasma potential of $-4 \mathrm{~V}$ measured by a Langmuir probe, taking into account the predominant ion species of $\mathrm{D}_{2}^{+}$. Thus, the energy of $\mathrm{D}$ and He ions was $98 \mathrm{eV} / \mathrm{D}$ and $196 \mathrm{eV} / \mathrm{He}$, respectively. The target current was $0.33 \mathrm{~A}$ and the plasma 'beam' had a diameter of about $30 \mathrm{~mm}$. The ion flux in the central area of the beam was $5 \times 10^{21} \mathrm{D} / \mathrm{m}^{2} \mathrm{~s}$. During plasma exposure, the temperature of the $\mathrm{W}$ target was 360 $400 \mathrm{~K}$.

To study sputtering of tungsten exposed to helium-seeded D plasmas generated in $\mathrm{He}+\mathrm{D}_{2}$ gas mixtures with various He percentage, a $0.5 \mathrm{~mm}$ thick $\mathrm{W}$ foil with a size of $10 \times 10 \mathrm{~mm}^{2}$ was used. The weight loss of the target was measured with a micro balance having an accuracy of $\pm 1 \mu \mathrm{g}$. The percentage of $\mathrm{He}$ in the $\mathrm{He}+\mathrm{D}_{2}$ gas mixture was determined by means of a high resolution quadrupole mass-spectrometer (HRQMS) QMA 410 (Balzers Instruments). The sputtering yield, $Y$, of the $\mathrm{W}$ foil exposed to the pure $\mathrm{D}$ and He plasmas was determined to be $Y_{\mathrm{D}_{2}}=(1.2 \pm 0.6) \times 10^{-5} \mathrm{~W} / \mathrm{D}_{2}{ }^{+}$and $Y_{\mathrm{He}}=2.7 \pm 0.5 \times 10^{-4}$ $\mathrm{W} / \mathrm{He}^{+}$, respectively. The very low erosion yield for $\mathrm{D}$ for ion energies below the threshold of sputtering may be due to a small amount of impurity ions. A practically linear dependence of the sputtering yields on the percentage of $\mathrm{He}$ atoms in the $\mathrm{He}+\mathrm{D}_{2}$ gas was found which allows the conclusion that the He ion percentage in the plasmas approximates the He atom percentage in the gas mixtures [11].

In order to collect sputtered particles, polished Si wafers and re-crystallized $\mathrm{W}$ and stainless steel (SS) SUS $304^{2}$ plates were fixed on two stainless steel holders equipped with inside-mounted ceramic heaters. These holders were placed at a distance of $40 \mathrm{~mm}$ from the sputtered $\mathrm{W}$ disc at a scattering angle of about $145^{\circ}$ (about $35^{\circ}$ to the $\mathrm{W}$ disc

\footnotetext{
${ }^{2}$ Coefficient of thermal expansion of SUS 304 is $17.2-18.4 \mathrm{ppm} /{ }^{\circ} \mathrm{C}$.
} 
surface normal). The negative bias voltage of $-200 \mathrm{~V}$ was applied to the substrate holders, and the back side of the holders was in contact with the plasma beam periphery; thus, the holders were passively heated up to about $400 \mathrm{~K}$. The third holder with the Si and W substrates was placed on the inner wall on the LPG vacuum chamber at a distance of 120 $\mathrm{mm}$ from the $\mathrm{W}$ cathode. This holder was grounded, and the temperature of the substrates on this holder did not exceed $323 \mathrm{~K}$.

\subsection{Diagnostics of the deposition layers}

Deuterium depth profiles in the deposition layers were measured at IPP, Garching by means of the $\mathrm{D}\left({ }^{3} \mathrm{He}, \alpha\right) \mathrm{H}$ nuclear reaction, where both the $\alpha$ particles and protons were analyzed. The $\alpha$ spectrum was transformed into a $\mathrm{D}$ depth profile using the program SIMRNA [12]. To determine the D concentration at depths greater than $0.5 \mu \mathrm{m}$, an analyzing beam of ${ }^{3} \mathrm{He}$ ions with energies varied from 0.69 to $2.0 \mathrm{MeV}$ was used [13]. The amount of deposited W atoms was determined by Rutherford backscattering spectrometry (RBS) [14].

The surface morphology of the deposition layers was examined at JAEA by a scanning electron microscope (SEM) (Real Surface View Microscope, KEYENCE VE9800 ) at a tilt angle of $45^{\circ}$. The impurity content in the layers was determined by RBS at IPP, Garching, and energy dispersive X-ray spectroscopy (EDX) at JAEA.

Thermal desorption spectroscopy (TDS) was performed ex-situ at JAEA in a separate vacuum chamber. An infrared heater was used to heat the samples at a ramp rate of $0.5 \mathrm{~K} / \mathrm{s}$ and the sample temperature was raised to $1300 \mathrm{~K}$. $\mathrm{HD},{ }^{4} \mathrm{He}$ and $\mathrm{D}_{2}$ molecules released during TDS runs were monitored by the HRQMS. To calculate the relative contribution of the recorded $\mathrm{HD}$ and $\mathrm{D}_{2}$ masses to the total release of deuterium, the partial currents of the HRQMS were normalized as described in Ref. [15]. Standard $\mathrm{D}_{2}$ and He leaks with an inaccuracy lower than 10\% were employed to calibrate the HRQMS QMA 410 after each TDS analysis.

The mechanical stability of the W layers deposited in the LPG on the SS and W substrates at $T=423$ and $523 \mathrm{~K}$, respectively, was examined by heating to the proposed maximum operation temperatures for tungsten and stainless steel components in the ITER divertor $[16,17]$. Therefore, the $\mathrm{W}$ layer on the $\mathrm{W}$ substrate was heated to $1300 \mathrm{~K}$, 
whereas the layer on the SS substrate was heated to $673 \mathrm{~K}$. The heating was performed at a heating rate of $0.5 \mathrm{~K} / \mathrm{s}$.

\section{Results}

\subsection{Composition, morphology and mechanical stability of $W$ deposition layers}

\subsubsection{Thick $W$ layers deposited with the use of magnetron plasma}

In the case of sputtering of a $\mathrm{W}$ cathode with magnetron plasmas, the $\mathrm{W}$ deposition rate was determined to be $(5.0 \pm 2.0) \times 10^{18}$ at. $\mathrm{m}^{-2} \mathrm{~s}^{-1}$ for the pure $\mathrm{D}$ plasma and $(6.5 \pm 2.0) \times 10^{19}$ at. $\mathrm{m}^{-2} \mathrm{~s}^{-1}$ for the Ar-seeded $\mathrm{D}$ plasma. The low deposition rate for sputtering with the pure D plasma at D ion energies below the threshold of sputtering may be explained by the presence of oxygen and carbon ions in the plasma due to poor vacuum conditions in the magnetron system. Assuming that the $\mathrm{W}$ deposition layers have densities approaching the $\mathrm{W}$ theoretical density, the thickness of the layers is estimated to be about 0.4 and $0.9 \mu \mathrm{m}$ for deposition with the pure D and Ar-seeded D plasmas, respectively.

According to RBS and EDX measurements, the deposition layers contain impurities, mainly oxygen. The oxygen concentration varies from 0.20 to $0.35 \mathrm{O} / \mathrm{W}$ (in units of the atomic concentration ratio) for the layers deposited with the use of the Ar-seeded D plasma, and from 0.30 to $0.60 \mathrm{O} / \mathrm{W}$ in the case of the pure D plasma. Oxygen is thought to be introduced into the $\mathrm{W}$ layers during the deposition process. The carbon concentration in the layers is below $0.15 \mathrm{C} / \mathrm{W}$. In the layers deposited with the use of the Ar-seeded D plasma, the Ar concentration is below the RBS detection limit of $10^{-2} \mathrm{Ar} / \mathrm{W}$.

The surface of the $\mathrm{W}$ layers deposited with the use of the pure D magnetron plasma at $T \leq 523 \mathrm{~K}$ is generally smooth and characterized by metallic lustre. However, rounded areas of peeling with sizes of 5-20 $\mu \mathrm{m}$ are observed on the surface after deposition at $T \leq$ $423 \mathrm{~K}$ (Fig. 1 a for $353 \mathrm{~K}$ ). As the substrate temperature rises, the areal density of the peeling increases. For the layers deposited at $T=613$ and $653 \mathrm{~K}$, the peeling of the layer occupies about $40 \%$ of the surface (Fig. $1 \mathrm{~b}$ for $653 \mathrm{~K}$ ). After post-deposition heating to $1300 \mathrm{~K}$, the thick W layers $(0.5-1 \mu \mathrm{m})$ demonstrate flaking-off and fracturing (Fig. 2). SEM images show that flakes with sizes of 20-100 $\mu \mathrm{m}$ were formed during the heating. Since the $\mathrm{Cu}$ intermediate layer is observed on the surface after the flaking-off, it is 
believed that the cracking and exfoliation can be explained by the different coefficients of thermal expansion for $\mathrm{Cu}$ and $\mathrm{W}$ layers.

The $\mathrm{W}$ layers deposited with the use of the Ar-seeded D plasma demonstrate the same dependence of the surface morphology on the substrate temperature as the layers prepared by sputtering with the pure D plasma. However, these layers were not subjected to the post-deposition heating.

\subsubsection{Thin W layers deposited with the use of LPG plasma}

It must be remembered that $\mathrm{W}$ layers were deposited in the linear plasma generator with the use of the helium-seeded D plasma with $10 \%$ of He ions. The deposition rate of $\mathrm{W}$ atoms on a substrate placed at a distance of $40 \mathrm{~mm}$ from the sputtered $\mathrm{W}$ target was determined to be about $(1.6 \pm 0.4) \times 10^{16}$ at. $\mathrm{m}^{-2} \mathrm{~s}^{-1}$. The deposition processes occurred over $82 \mathrm{hrs}$, and, according to the RBS measurements, the thickness of W layers deposited at a distance of about $40 \mathrm{~mm}$ was $(4.5-5.0) \times 10^{21} \mathrm{~W} / \mathrm{m}^{2}$ (or 70-80 $\mathrm{nm}$, assuming a layer density close to the $\mathrm{W}$ theoretical density). For $\mathrm{W}$ layers deposited at a distance of $120 \mathrm{~mm}$, the deposition rate was about 10 times lower than for layers formed at a distance of $40 \mathrm{~mm}$.

Due to sputtering of the Mo ring holding the $\mathrm{W}$ disc, the $\mathrm{W}$ layers deposited in the linear plasma generator contain molybdenum with a Mo to $\mathrm{W}$ atomic ratio of 0.1 . According to ex-situ EDX analysis, the oxygen concentration in these layers is 0.08-0.11 $\mathrm{O} /(\mathrm{W}+\mathrm{Mo})$. However, color transformation of the layer surface from metallic luster to yellowish tint within 10 min after taking out of the substrates from the LPG vacuum chamber implies that the oxygen concentration in $\mathrm{W}$ layers during deposition process would have been lower. It should be noted that the background vacuum pressure in the LPG chamber was about $10^{-6} \mathrm{~Pa}$.

No blisters and no areas of cracks exist on the layers deposited at temperatures $T \leq$ $623 \mathrm{~K}$. However, sparse areas of pilling, 1-10 $\mu \mathrm{m}$ in size, are observed on the surface of $\mathrm{W}$ layers deposited on the re-crystallized W substrate at temperatures of 523-623 K; see Fig. 3 a for the layer deposited at $523 \mathrm{~K}$.

SEM examination of mechanical stability of the $\mathrm{W}$ layers deposited on the SS substrate at $T=423 \mathrm{~K}$ and on the $\mathrm{W}$ substrate at $T=523 \mathrm{~K}$ after post-deposition heating to 673 and $1300 \mathrm{~K}$, respectively, shows that the heating does not change practically the surface morphology of the layers; compare Figures $3 \mathrm{a}$ and $3 \mathrm{~b}$. No areas of layer 
exfoliation and cracks are observed after the heating. It may be concluded therefore that adhesion of about $100 \mathrm{~nm}$ thick $\mathrm{W}$ layers deposited on $\mathrm{W}$ and stainless steel is sufficiently high to prevent formation of $\mathrm{W}$ dust during heating of these substrates.

\section{2. $D$ retention in $W$ layers}

\subsubsection{W layers deposited with the use of magnetron plasma}

In W layers deposited by magnetron sputtering with pure D and Ar-seeded D plasmas, the deuterium is distributed practically homogeneously throughout the whole thickness. However, the $\mathrm{D}$ concentration decreases by more than two orders of magnitude at the interface between the $\mathrm{W}$ layer and the $\mathrm{Cu}$ interlayer. With an increase in substrate temperature, the deuterium concentration in the $\mathrm{W}$ layer varies from $0.1 \mathrm{D} / \mathrm{W}$ (in units of the atomic concentration ratio) at $333 \mathrm{~K}$ to about $3 \times 10^{-3} \mathrm{D} / \mathrm{W}$ at $653 \mathrm{~K}$ for deposition by sputtering with the pure D plasma, and from about $0.07 \mathrm{D} / \mathrm{W}$ at $303 \mathrm{~K}$ to about $2 \times 10^{-4}$ $\mathrm{D} / \mathrm{W}$ at $613 \mathrm{~K}$ for deposition with the use of the Ar-seeded D plasma (Fig. 4).

TDS spectra for the W layers deposited at substrate temperatures from 353 to $523 \mathrm{~K}$ by sputtering with the use of the magnetron pure D plasma are shown in Fig. 5. These spectra are not representing single peaks, but rather peaks with shoulders or double peaks at $620-670 \mathrm{~K}$ and $760-770 \mathrm{~K}$, suggesting the presence of multiple trap energies. According to Poon et al. [18], these two peaks may correspond to trapping of two and one D atoms per vacancy, respectively.

For the $\mathrm{W}$ layer deposited at $T=353 \mathrm{~K}$, numerous bursting release peaks appear at temperatures in the range from 600 to $650 \mathrm{~K}$ (Fig. 5), while for deposition at $T \geq 423 \mathrm{~K}$ these bursting peaks are not observed. This may imply that in the $\mathrm{W}$ layers deposited at near-room temperature, a small fraction of deuterium is accumulated in gaseous form, probably in macroscopic voids and cracks.

\subsubsection{W layers deposited with the use of LPG plasma}

In $\mathrm{W}$ layers deposited in the linear plasma generator by sputtering with the heliumseeded D plasma, the $\mathrm{D}$ concentration is about $0.16 \mathrm{D} / \mathrm{W}$ for deposition at $323 \mathrm{~K}$ and reduces to about $0.04 \mathrm{D} / \mathrm{W}$ at $623 \mathrm{~K}$ (Fig. 4). The deuterium TDS spectra are characterized 
by desorption peaks positioned at 700-800 K, depending on the deposition temperature (Fig. 6 a). The second low-intensity peak at $950 \mathrm{~K}$ is observed only in the spectrum for the $\mathrm{W}$ layer deposited at $323 \mathrm{~K}$. The desorption peak at $700-800 \mathrm{~K}$ may be attributed to detrapping of $\mathrm{D}$ atoms from vacancies [18], while the high temperature peak at $950 \mathrm{~K}$ may correspond to the release of D atoms initially bound on the surface of voids [19]

TDS spectra show that the $\mathrm{W}$ layers contain $\mathrm{He}$ atoms in addition to deuterium (Fig. $6 \mathrm{~b}$ ). The concentration of $\mathrm{He}$ atoms is determined to be about $0.4 \mathrm{He} / \mathrm{W}$ for deposition at $323 \mathrm{~K}$ and about $0.08 \mathrm{He} / \mathrm{W}$ for deposition at $623 \mathrm{~K}$ (Fig. 4). It is pertinent to note that $\mathrm{He}$ atoms are present in the $\mathrm{W}$ layers deposited on both negative biased and grounded substrates. It may be concluded, therefore, that the growing layers are bombarded by energetic deuterium and helium atoms reflected from the $\mathrm{W}$ target. Simultaneous irradiation with He and D ions creates additional traps for D atoms $[20,11]$, thus increasing the D concentration in the $\mathrm{W}$ layers.

\section{Discussion}

A following scaling equation was proposed recently by De Temmerman and Doerner [6] to describe the influence of the conditions during the $\mathrm{W}$ and $\mathrm{D}$ co-deposition process (substrate temperature, incident $\mathrm{D}$ particle energy and $\mathrm{W}$ deposition rate) on the $\mathrm{D}$ concentration in the deposited layers:

$$
\frac{\mathrm{D}}{\mathrm{W}}=5.7 \cdot 10^{-8} \cdot r_{d}^{-0.41 \pm 0.1} \cdot E_{n}^{1.88 \pm 0.4} \cdot \exp \left(\frac{779 \pm 220}{T}\right),
$$

where $r_{d}$ is the $\mathrm{W}$ deposition rate (in units of $10^{19} \mathrm{at} \cdot \mathrm{m}^{-2} \cdot \mathrm{s}^{-1}$ ), $E_{n}$ is the average energy of the incoming D particles on the substrate (in $\mathrm{eV}$ ), and $T$ is the substrate temperature (in $\mathrm{K}$ ). $E_{n}$ is determined using the following formula [21]:

$$
E_{n}\left(E_{0}\right)=E_{0} \frac{R_{E}\left(E_{0}\right)}{R_{N}\left(E_{0}\right)}
$$


where $E_{0}$ is the energy of the ions impinging on the $\mathrm{W}$ target, $R_{N}$ is the fraction of backscattered particles, and $R_{E}$ is the energy reflection coefficient.

For W layers deposited in the linear plasma generator with the use of the He-seeded D plasma, the temperature dependence of the D concentration is actually approximated by the curve proportional to $\exp (779 / T)$ (Fig. 4). However, for W layers deposited with the use of the magnetron pure $\mathrm{D}$ and Ar-seeded D plasmas, it is found that $\mathrm{D} / \mathrm{W}$ is proportional to $\exp \left(270 \pm 30 / T^{0.5}\right)$ (Fig. 4). It may be suggested that co-deposition of oxygen into these layers (up to $0.60 \mathrm{O} / \mathrm{W}$ ) changes deuterium de-trapping characteristics. In the $\mathrm{W}$ layers produced in the present study with the relatively high oxygen content, a decrease of the D concentration with increasing substrate temperature is more pronounced than that for $\mathrm{W}$ layers of De Temmerman and Doerner [6] where the oxygen concentration was significantly lower ( $\mathrm{O}$ and $\mathrm{C}$ impurities were lower than 5 at.\%).

A decrease of the $\mathrm{D}$ concentration in $\mathrm{W}$ layers with increasing $\mathrm{W}$ deposition rate, originally observed by De Temmerman and Doerner [6], was also observed in our experiments for the $\mathrm{W}$ layers deposited by sputtering with the magnetron pure $\mathrm{D}$ and Arseeded D plasmas and LPG helium-seeded D plasma (Fig. 7). In our experiments, however, in the temperatures range from 313 to $533 \mathrm{~K}$ and at deposition rates above $0.5 \times 10^{19}$ at. $\mathrm{m}^{-2} \cdot \mathrm{s}^{-1}, \mathrm{D} / \mathrm{W}$ was found to be proportional to $r_{d}{ }^{-0.8}$ rather than to $r_{d}{ }^{-0.41}$ as seen in [6] (Fig. 7). At lower deposition rates $\left(\leq 0.5 \times 10^{19} \mathrm{at} \cdot \mathrm{m}^{-2} \cdot \mathrm{s}^{-1}\right)$, the dependence of the D concentration on the $\mathrm{W}$ deposition rate demonstrates a transition to a plateau resulting from saturation of the $\mathrm{W}$ layers with $\mathrm{D}$ atoms.

\section{Summary}

Surface morphology of tungsten layers deposited by deuterium plasma sputtering depends on the layer formation conditions. Tungsten layers above $0.4 \mu \mathrm{m}$ in thickness deposited onto copper substrates demonstrate areas of pilling and, after heating up to $1300 \mathrm{~K}$, flaking-off and fracturing. The cracking and exfoliation can be explained by the different coefficients of thermal expansion for $\mathrm{Cu}$ and $\mathrm{W}$ layers.

For thin W layers $(\leq 80 \mathrm{~nm})$ deposited onto stainless steel and tungsten substrates, no areas of flaking-off and fracturing exist both after deposition at substrate temperatures $\leq$ 
$623 \mathrm{~K}$ and after post-deposition heating to $673 \mathrm{~K}$ for the stainless steel substrate and to $1300 \mathrm{~K}$ for the tungsten substrate.

The concentration of deuterium in the tungsten layers was found to decrease with substrate temperature and tungsten deposition rate. For W layers with relatively high concentration of oxygen (0.20-0.60 O/W), which were deposited in poor vacuum conditions, a decrease of the $\mathrm{D}$ concentration with increasing substrate temperature is more pronounced than that for $\mathrm{W}$ layers deposited in good vacuum conditions. An empirical equation proposed in [6] but with alternative activation parameters has been used here to describe the evolution of the $\mathrm{D} / \mathrm{W}$ ratio with the substrate temperature for the oxygencontaining W layers deposited in a magnetron system. However, the substrate-temperature dependence of the $\mathrm{D}$ concentration for the $\mathrm{W}$ layers deposited in good vacuum conditions in the linear plasma generator is similar to what was previously observed by De Temmerman and Doerner [6]. It has also been found that at temperatures in the range from 313 to $533 \mathrm{~K}$ and deposition rates $r_{\mathrm{d}}$ above $0.5 \times 10^{19} \mathrm{at} \cdot \mathrm{m}^{-2} \cdot \mathrm{s}^{-1}, \mathrm{D} / \mathrm{W}$ is proportional to $r_{d}^{-0.8}$ rather than to $r_{d}^{-0.41}$ as reported in [6].

\section{Acknowledgements}

The portion of this work performed at JAEA was supported by ITER International Organization under Task Agreement ITER/TA/08/490. The authors thank B. Tyburska, J. Dorner and M. Fußeder (IPP Garching) for technical assistance with the ${ }^{3} \mathrm{He}$ beam analyses. 


\section{Figure capture}

Figure 1. SEM images of $\mathrm{W}$ layers deposited onto $\mathrm{Cu} / \mathrm{Si}$ substrates at temperatures of $353 \mathrm{~K}$ (a) and $653 \mathrm{~K}$ (b) with the use of magnetron pure D plasma. The magnification of all images is the same.

Figure 2. SEM images of $\mathrm{W}$ layers deposited onto $\mathrm{Cu} / \mathrm{Si}$ substrates at temperatures of $353 \mathrm{~K}$ (a) and $653 \mathrm{~K}(\mathrm{~b})$ with the use of magnetron pure D plasma after post-deposition heating up to $1300 \mathrm{~K}$. The magnification of all images is the same.

Figure 3. SEM images of $\mathrm{W}$ layers deposited onto re-crystallized $\mathrm{W}$ at temperature of $523 \mathrm{~K}$ by sputtering with LPG helium-seeded D plasma before (a) and after postdeposition heating up to $1300 \mathrm{~K}$ (b). The magnification of all images is the same.

Figure 4. Deuterium and helium concentration in $\mathrm{W}$ layers deposited by sputtering with magnetron (MAG) pure D and Ar-seeded D plasmas and LPG helium-seeded D plasma, as a function of substrate temperature. The deuterium concentration was measured by nuclear reaction analysis, whereas the He concentration was determined by comparing integrals of deuterium and helium TDS release rates over time. For comparison, the temperature dependence of the $\mathrm{D}$ concentrations in $\mathrm{W}$ layers deposited with the use of magnetron Arseeded D plasmas (data by De Temmerman and Doerner [6]) is also shown. The solid lines represent exponential dependences of the $\mathrm{D}$ concentration on the substrate temperature, as indicated in the Figure.

Figure 5. Deuterium TDS spectra for the $\mathrm{W}$ layers deposited at 353, 423 and $523 \mathrm{~K}$ by sputtering with magnetron pure D plasma. The TDS heating rate was $0.5 \mathrm{~K} / \mathrm{s}$. Note that the deuterium release rate is normalized to one $\mathrm{W}$ atom. 
Figure 6. Deuterium (a) and helium (b) TDS spectra for W layers deposited at substrate temperatures of 323, 423 and $523 \mathrm{~K}$ by sputtering with LPG helium-seeded D plasma. The TDS heating rate was $0.5 \mathrm{~K} / \mathrm{s}$. Note that the deuterium and helium release rates are normalized to one $\mathrm{W}$ atom.

Figure 7. Deuterium concentration in $\mathrm{W}$ layers deposited at various substrate temperatures with the use of magnetron (MAG) pure D and Ar-seeded D plasmas and LPG heliumseeded $\mathrm{D}$ plasma, as a function of the $\mathrm{W}$ deposition rate. For comparison, data by De Temmerman and Doerner [6] are also shown. The solid line is proportional to $r_{d}^{-0.8}$, where $r_{d}$ is the $\mathrm{W}$ deposition rate (in units of $10^{19} \mathrm{at} \cdot \mathrm{m}^{-2} \cdot \mathrm{s}^{-1}$ ). 


\section{References}

[1] H. Bolt, V. Barabash, W. Krauss, J. Linke, R. Neu, S. Suzuki, N. Yoshida, J. Nucl. Mater. 329-333 (2004) 66.

[2] S. Rosanvallon, C. Grisolia, G. Counsell, S.H. Hong, F. Onofri, J. Worms, J. Winter, B.M. Annaratone, G. Maddaluno, P. Gasior, Fusion Eng. Des. (2008).

[3 ] C.H. Skinner, A.A. Haasz, V.Kh. Alimov, N. Bekris, R.A. Causey, R.E.H. Clark, J.P. Coad, J.W. Davis, R.P. Doerner, M. Mayer, A. Pisarev, J. Roth, T. Tanabe, Fusion Sci. Technol. 54 (2008) 891.

[4] M. Mayer, R. Behrisch, H. Plank, J. Roth, G. Dollinger, C.M. Frey, J. Nucl. Mater. 230 (1996) 67.

[5] K. Katayama, K. Imaoka, T. Okamura, M. Nishikawa, Fusion Eng. Des. 82 (2007) 1645.

[6] G. De Temmerman, R.P. Doerner, J. Nucl. Mater. 389 (2009) 479.

[7] V.Kh. Alimov, D.A. Komarov, J. Nucl. Mater. 313-316 (2003) 599.

[8] V.Kh. Alimov, D.A. Komarov, J. Roth, M. Mayer, S. Lindig, J. Nucl. Mater. 349 (2006) 282.

[9] G.-N. Luo, W.M. Shu, H. Nakamura, S. O’hira, M. Nishi, Rev. Sci. Instrum. 75 (2004) 4374.

[10] G.-N. Luo, W.M. Shu, H. Nakamura, S. O’hira, T. Hayashi, M. Nishi, Characteristics of a low energy and high flux compact plasma source and preliminary results in studying surface modification of tungsten irradiated by the source, JAERI-Tech Report, 2004-031.

[11] V.Kh. Alimov, W.M. Shu, J. Roth, K. Sugiyama, S. Lindig, M. Balden, K. Isobe, and T. Yamanishi, Phys. Scr. T 138 (2009) 014048.

[12] M. Mayer, SIMNRA User's Guide, Tech. Rep. IPP 9/113, Garching, 1997.

[13] V.Kh. Alimov, M. Mayer, J. Roth, Nucl. Instr. and Meth. B 234 (2005) 169.

[14] W.K. Chu, J.W. Mayer, M.A. Nicolet, Backscattering Spectrometry, Academic Press, 1978.

[15] P. Franzen, B.M.U. Scherzer, W. Möller, Nucl. Instr. and Meth. B67 (1992) 536. 
[16] G. Federici, J.N. Brooks, D.P. Coster, G. Janeschitz, A. Kukushkin, A. Loarte, H.D. Pacher, J. Stober, C.H. Wu, J. Nucl. Mater. 290-293 (2001) 260.

[17] T. Hirai (Divertor Section, ITER Organization), Private communication.

[18] M. Poon, A.A. Haasz, J.W. Davis, J. Nucl. Mater. 374 (2008) 390.

[19] A. van Veen, J. de Vries, D. Segers, G.J. Rozing, in: P.C. Jain, R.M. Singru and K.P. Gopinathan (Eds.), Positron Annihilation, World Scientific Publ. Co., Singapore, 1985, p. 543.

[20] H.T. Lee, A.A. Haasz, J.W. Davis, R.G. Macaulay-Newcombe, D.G. Whyte, G.M. Wright, J. Nucl. Mater. 363-365 (2007) 898.

[21] W. Eckstein, Calculated Sputtering, Reflection and Range Values, IPP-Report 9/132, Garching, Germany (2002). 
a

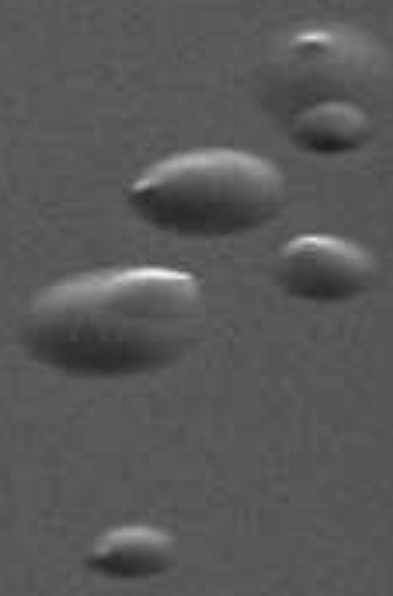

$20 \mu \mathrm{m}$

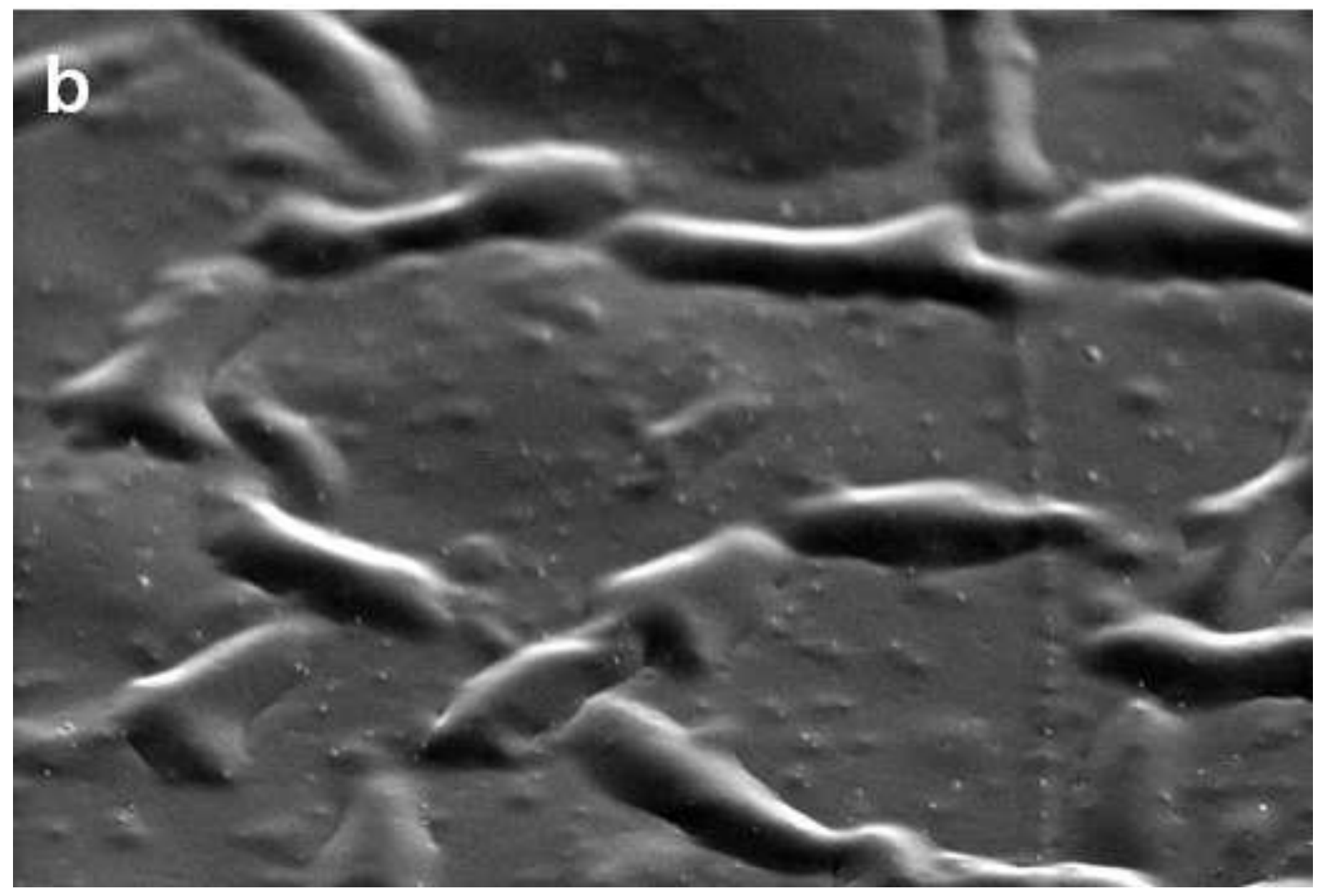


a
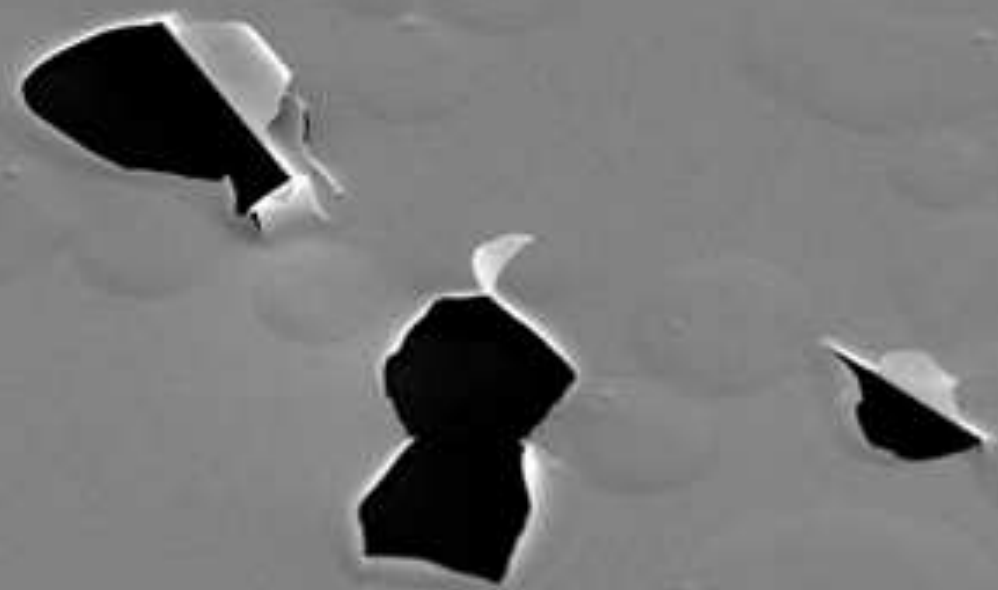

$80 \mu \mathrm{m}$

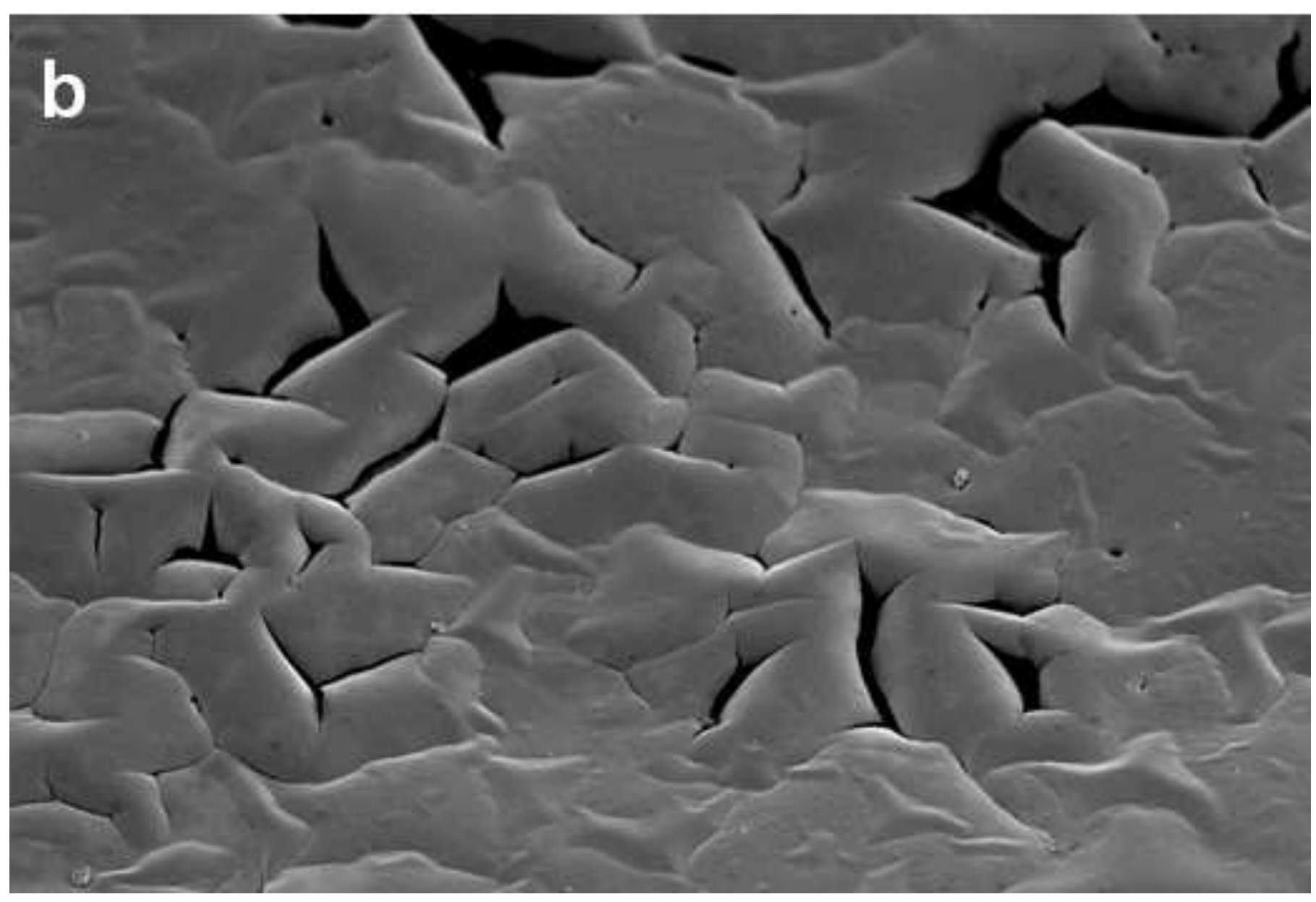



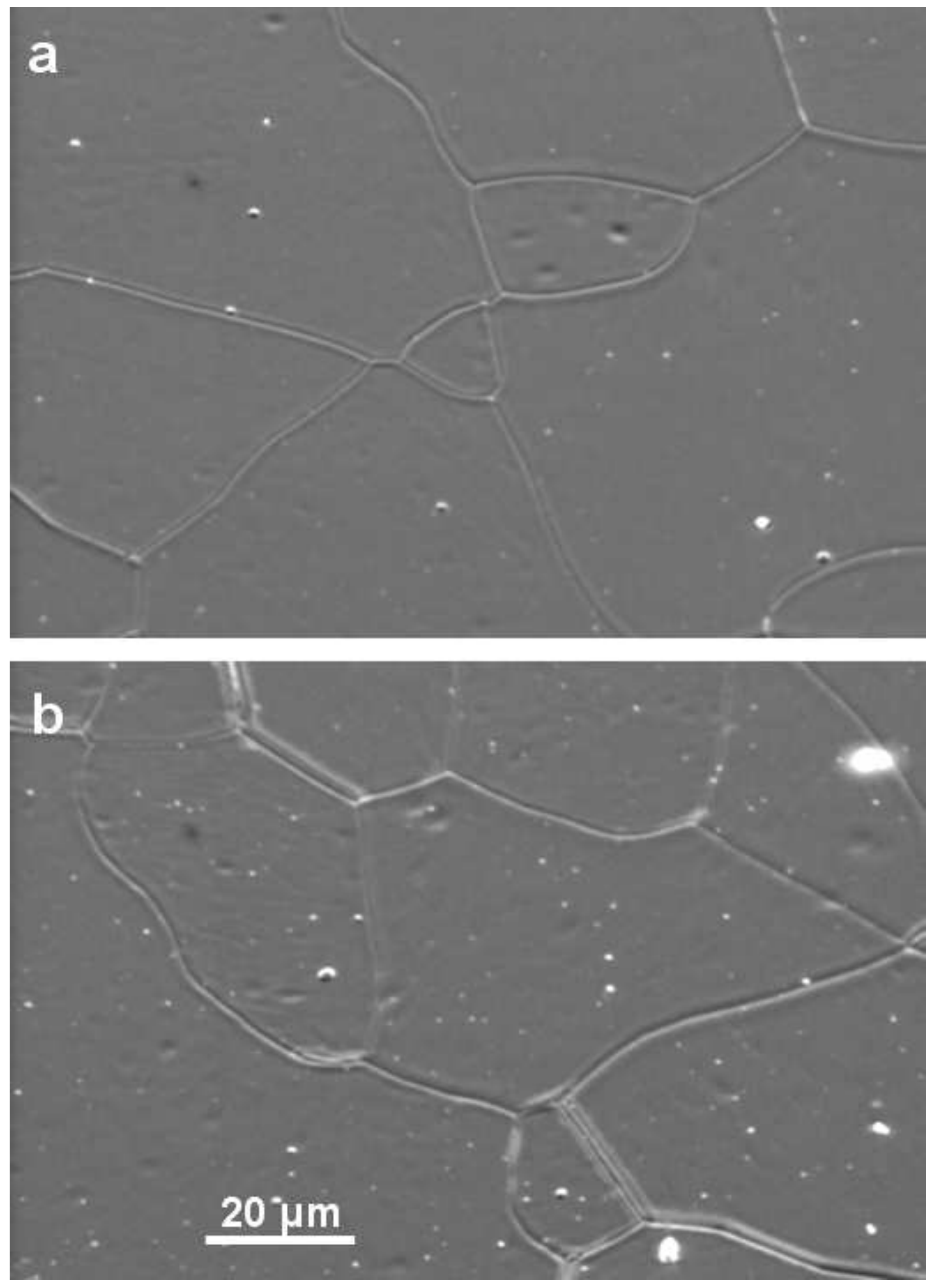


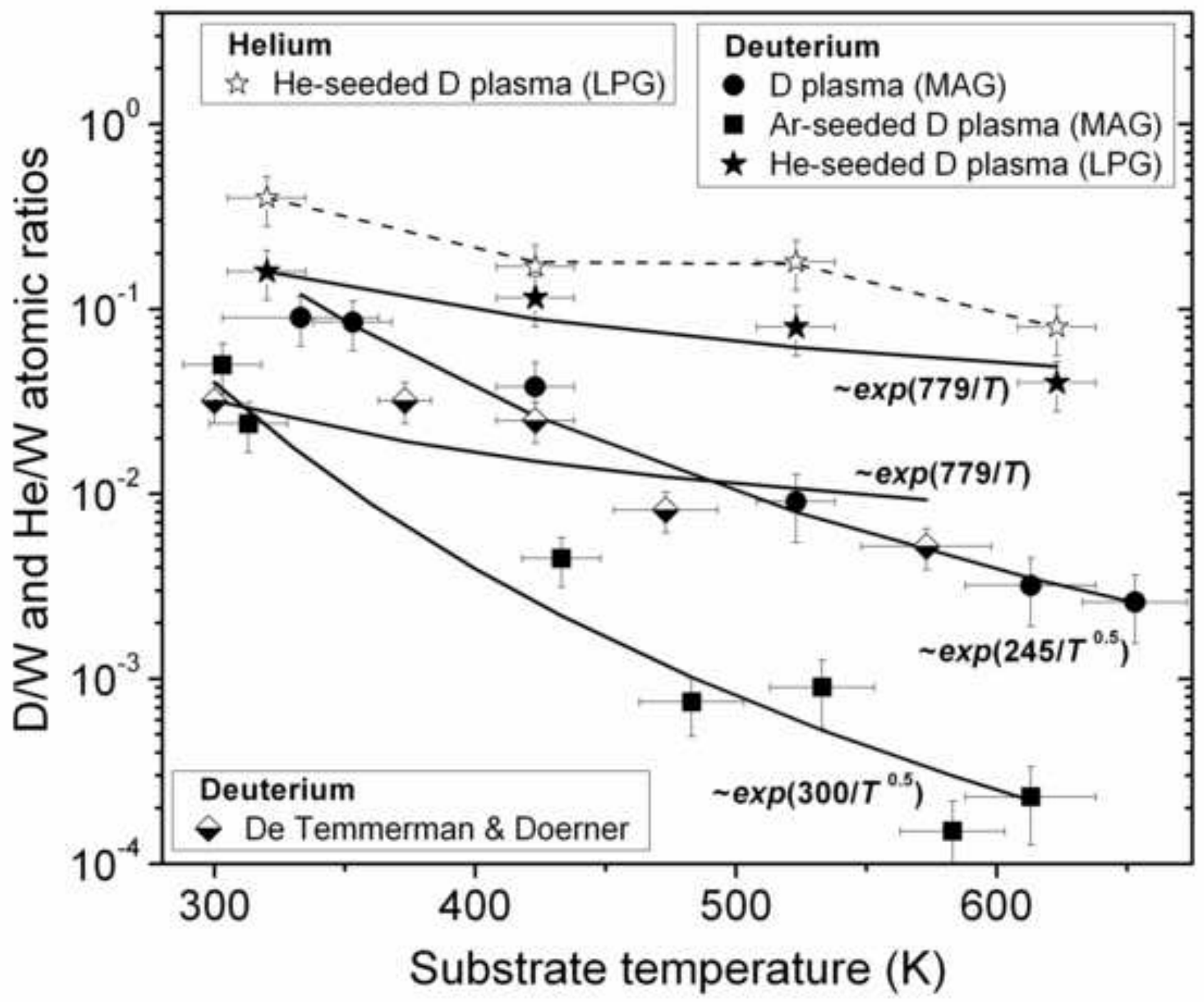




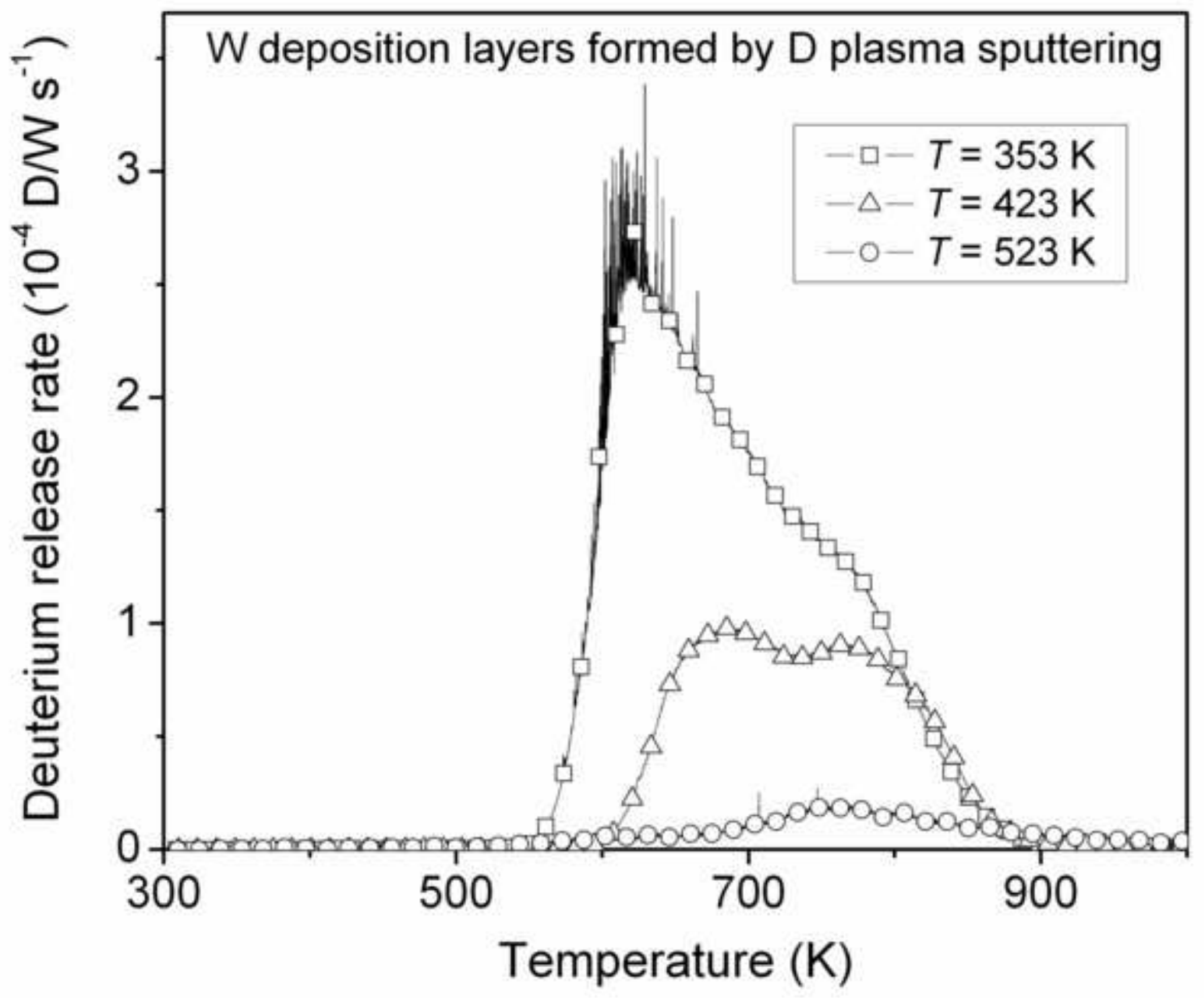




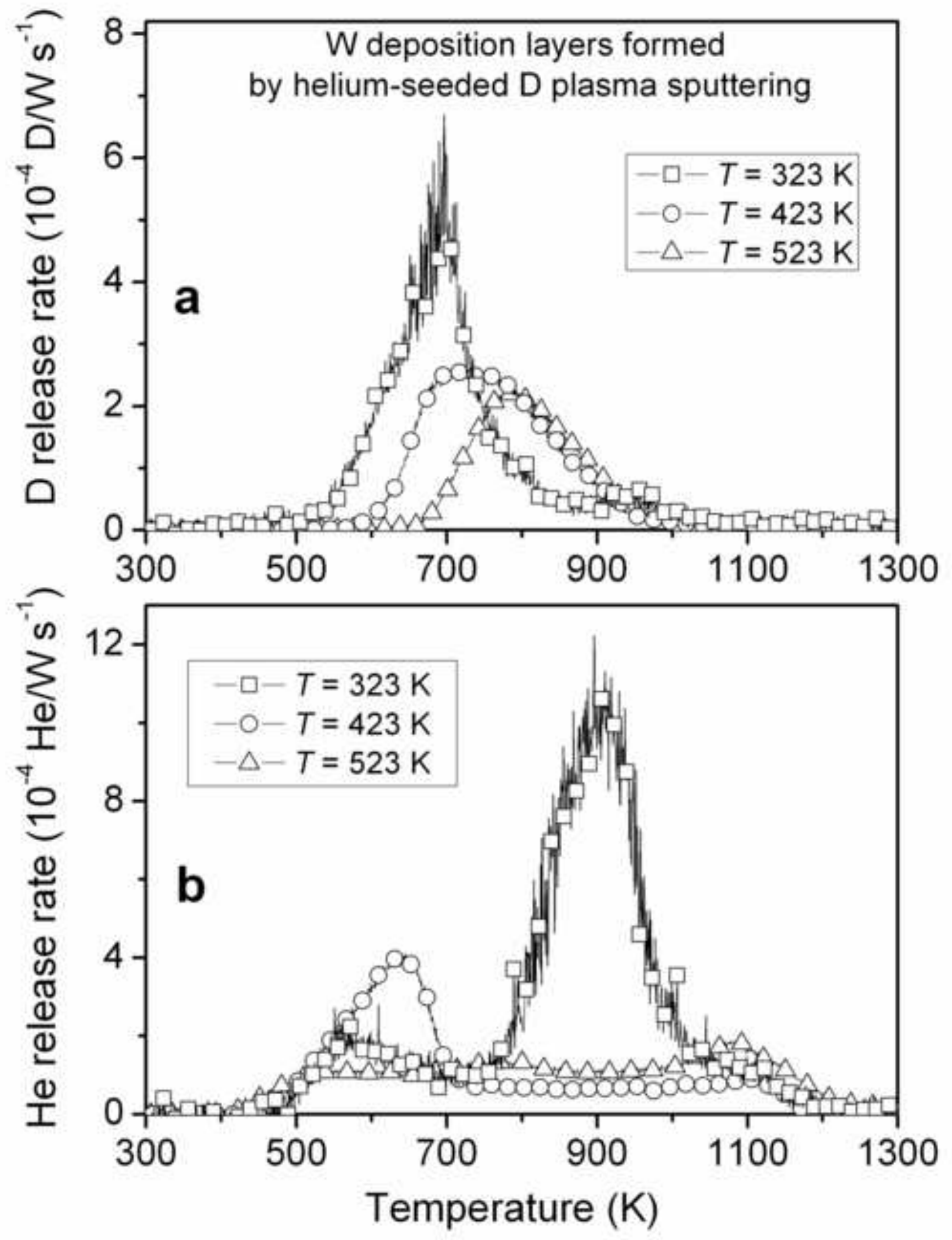




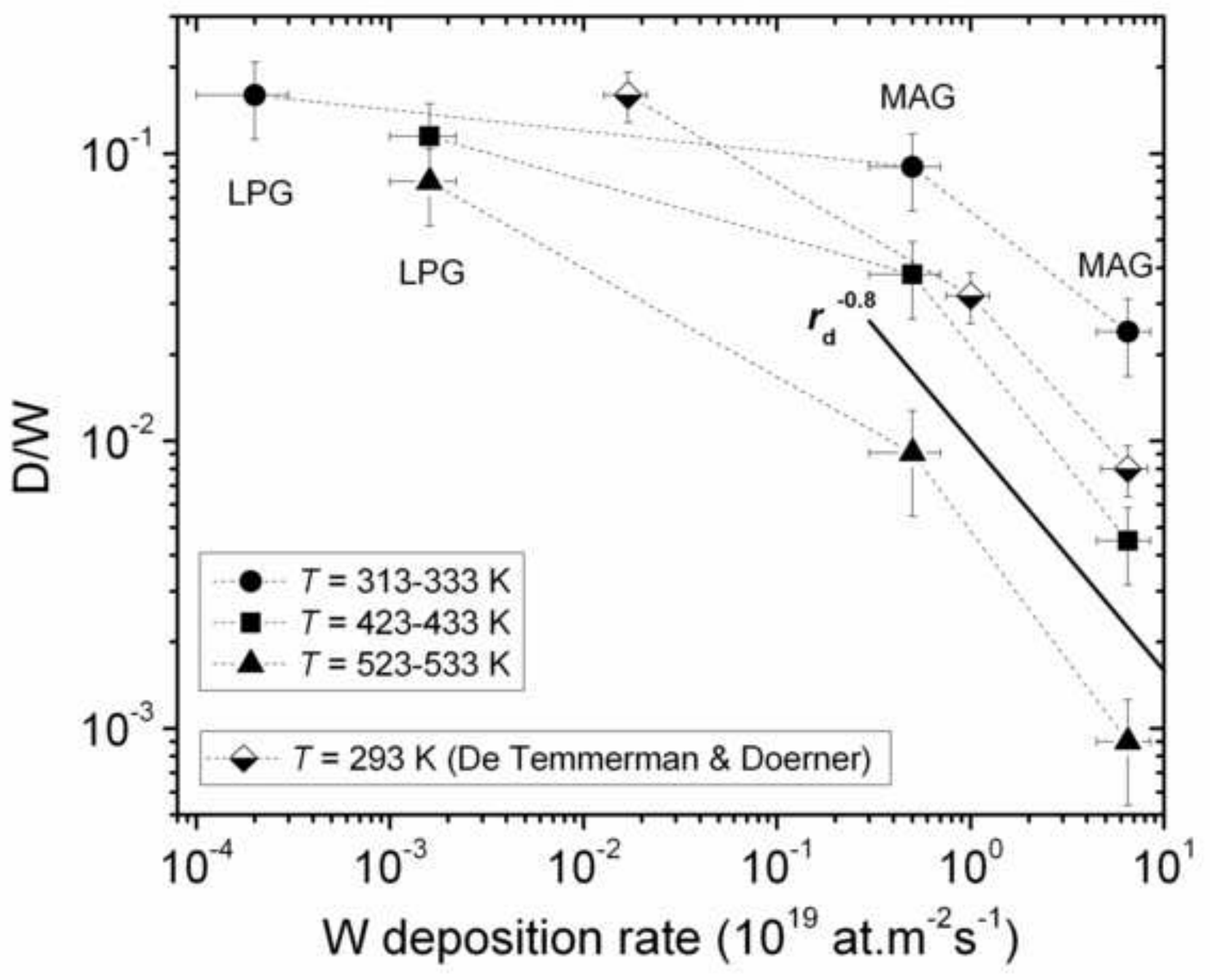

